Results: From December 2018 to November 2019, 230 AAV patients were recruited in 6 non-academic and 3 academic hospitals (120 vs 110 patients respectively). Differences in clinical diagnoses (GPA, MPA and eGPA) were observed between non-academic and academic centers $(p=0.05)$, which was mainly caused by a higher number of MPA patients in non-academic centers. The year of diagnosis was comparable (median 2013 [2009-2016], $\mathrm{p}=0.150$ ). The median follow up since diagnosis was 4.8 years [1.8-9.6] with a median in-hospital time-to-diagnosis of 13 days [2-50]. Patients were diagnosed at a mean age of 63 years $( \pm 11.18)$ in non-academic centers and 53 years $( \pm 16.92)$ in academic centers $(p<0.001)$. Besides steroids, oral cyclophosphamide was the most preferred drug (54\%) for induction therapy, whereas rituximab was given significantly more often as (part of the) induction therapy in patients treated in academic centers compared to patients in non-academic centers $(27 \%$ vs $8 \%$, $\mathrm{p}<0.001)$. In non-academic centers pneumocystis pneumonia (PCP) prophylaxis was prescribed significantly less ( $76 \%$ vs $91 \%, p=0.003)$. Also, screening for Staphylococcus aureus carriership was significantly less $(17 \%$ vs $68 \%, p<0.001)$. With respect to mortality and co-morbidity, 22 patients (10\%) died, 100 patients $(44 \%)$ had at least one infection and 24 patients $(10 \%)$ suffered from at least one malignancy. We observed no significant differences on these endpoints between academic and non-academic centers.

Conclusion: The present study highlights important practice variation in the management of AAV between academic and non-academic hospitals in the Netherlands. A high proportion of patients is treated with oral cyclophosphamide as induction therapy while rituximab is increasingly used in academic centers. Rates of mortality, infections and malignancies were not different. Altogether, this study raises awareness into the variation of management for AAV patients and allows the identification of areas for improvement of clinical care for Dutch AAV patients.

Disclosure of Interests: Ebru Dirikgil: None declared, Abraham Rutgers: None declared, Sander Tas: None declared, Cornelis A. Verburgh: None declared, Darius Soonawala: None declared, A. Elisabeth Hak: None declared, Hilde H.F. Remmelts: None declared, Daphne IJpelaar: None declared, Gozewijn D. Laverman: None declared, Jacob M. van Laar Grant/research support from: MSD, Genentech, Consultant of: MSD, Roche, Pfizer, Eli Lilly, BMS, H.J. Bernelot Moens: None declared, Peter Verhoeven: None declared, Willem Jan W. Bos: None declared, Y.K. Onno Teng Grant/research support from: GSK, Consultant of: GSK, Aurinia Pharmaceuticals, Novartis DOI: 10.1136/annrheumdis-2020-eular.1297

\section{THU0305 \\ PREVALENCE AND CLINICAL OUTCOME OF INTERSTITIAL LUNG DISEASE IN ANCA ASSOCIATED VASCULITIS}

J. Fernandes Serodio*1,2, J. Hernández-Rodríguez ${ }^{1}$, G. Espígol-Frigolé ${ }^{1}$, M. Alba ${ }^{1}$, J. Marco-Hernández ${ }^{1}$, M. Sánchez ${ }^{3}, F$. Hernández-González ${ }^{4}$, J. Sellarés ${ }^{4}$, M. C. Cid ${ }^{1}$, S. Prieto-González ${ }^{1} .{ }^{1}$ Vasculitis Research Unit, Department of Systemic Autoimmune Diseases, Hospital Clínic de Barcelona, IDIBAPS, University of Barcelona, Barcelona, Spain; ${ }^{2}$ Department of Internal Medicine IV, Hospital Professor Doutor Fernando Fonseca, Amadora, Portugal; ${ }^{3}$ Department of Radiology, Hospital Clínic de Barcelona, Barcelona, Spain; ${ }^{4}$ Department of Pneumology, Hospital Clínic de Barcelona, Barcelona, Spain

Background: Lung involvement is frequent in ANCA-associated vasculitis (AAV). Classical lung manifestations consist of capillaritis with lung haemorrhage, inflammatory infiltrates and nodules. Interstitial lung disease (ILD) is increasingly recognized among patients with AAV. However, little is known concerning risk factors and clinical course of these patients.

Objectives: The aim of our study was to characterize the prevalence and clinical course of ILD in patients with AAV.

Methods: We have performed a clinical retrospective single-centre observational analysis (1990-2019) of all patients with the diagnosis of microscopic polyangiitis (MPA) and granulomatosis with polyangiitis (GPA) diagnosed according to 2018 Draft Classification Criteria for GPA and MPA'. Demographic, clinical and immunologic data were reviewed. Radiologic pattern of ILD were assessed by high-resolution-CT. Main outcome evaluated was overall-all survival.

Results: The study population consisted of 123 patients, $56 \%$ female, aged $59.3 \pm 18.2$ years old at the time of diagnosis. Clinical diagnosis was of MPA in $54 \%$ of patients and GPA in $46 \%$. While 108 (88\%) ANCA positive patients had PR3 $(n=25)$ or MPO $(n=83), 15(12 \%)$ patients had negative or atypical ANCA. Any lung involvement was present in $82(71 \%)$ and ILD was identified in $24(20 \%)$ of all patients. ILD pattern was of usual interstitial pneumonia (UIP) in 12 patients, non-specified interstitial pneumonia (NSIP) in 9 and chronic organizing pneumonia (OP) in 3 . There was an association between the presence of ILD and
ANCA specificity: MPO were present in $100 \%$ of patients with UIP and in $75 \%$ of patients with NSIP/OP $(p=0.017)$. Bronchiectasis were more prevalent among patients with ILD $(19 / 24 ; p<0.001)$. During the median follow-up time period of 68 (23-126) months, mortality was of $42 \%$ among patients with ILD-AAV compared with $11 \%$ in no ILD-AAV (log-rank $p=0.0001)$. On the multivariate Cox regression model, ILD was an independent predictor of mortality HR $2.95(95 \% \mathrm{Cl} 1.09-7.96$; $\mathrm{p}=0.033$ ).

Conclusion: ILD is a frequent manifestation of MPA and GPA patients. The presence of ILD, particularly UIP, is associated with ANCA-MPO and is a predictor of mortality. Therefore, a better management of fibrotic lung involvement in AAV is warranted.

\section{References:}

[1] Robson JC, Grayson PC, Ponte C, et al. Draft classification criteria for the ANCA associated vasculitides. Ann Rheum Dis 2018;77 (suppl 2):60-1.

Graph 1. Survival analysis of patients with AAV according to the presence of ILD

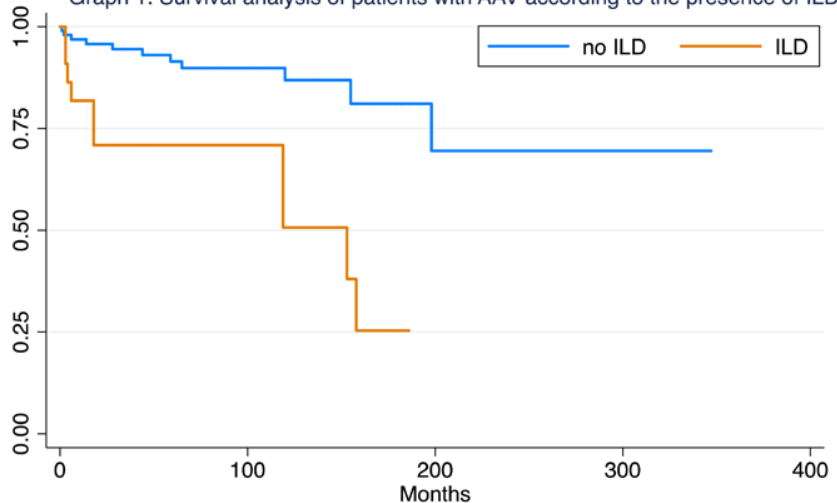

Patients with ILD-AAV have decreased survival when compared with patients with AAV and no ILD, log-rank test $p=0,0001$

Disclosure of Interests: João Fernandes Serodio: None declared, José Hernández-Rodríguez: None declared, Georgina Espígol-Frigolé: None declared, Marco Alba: None declared, Javier Marco-Hernández: None declared, Marcelo Sánchez: None declared, Fernanda Hernández-González: None declared, Jacobo Sellarés: None declared, Maria C. Cid Grant/research support from: Kiniksa Pharmaceuticals, Consultant of: Janssen, Abbvie, Roche, GSK, Speakers bureau: Vifor, Sergio Prieto-González: None declared DOI: 10.1136/annrheumdis-2020-eular.6211

\section{THU0306 ROLE OF 18-FDG PET/CT IN DIAGNOSIS AND FOLLOW UP OF LARGE VESSELS VASCULITIS}

L. Gigante ${ }^{1}$, D. Bruno ${ }^{1}$, V. Feudo ${ }^{2}$, S. L. Bosello ${ }^{1,3}$, L. Leccisotti ${ }^{4}$, A. Musto ${ }^{1}$, P. G. Cerasuolo ${ }^{1}$, A. Zoli ${ }^{1,3}$, A. Giordano ${ }^{2,4}$, E. Gremese ${ }^{1,3} .{ }^{1}$ Division of Rheumatology, Università Cattolica del Sacro Cuore, Rome, Italy; ${ }^{2}$ Division of Nuclear Medicine, Università Cattolica del Sacro Cuore, Rome, Italy; ${ }^{3}$ Division of Rheumatology, Fondazione Policlinico Universitario A. Gemelli-IRCCS, Rome, Italy; ${ }^{4}$ Division of Nuclear Medicine, Fondazione Policlinico Universitario A. Gemelli-IRCCS, Rome, Italy

Background: 18-FDG PET/CT is a functional imaging method which allows to identify inflammation of vessel walls. The use of PET in large vessels vasculitis(LVV) at disease onset and during follow up is still debate either to confirm clinical remission either to drive the therapy choice. American Society of Nuclear Cardiology (ASNC) recently advanced recommendations aimed to standardize the application of PET in LVV(1).

Objectives: The aim of our study was to assess the clinical role of PET performed in patients affected by LVV at the diagnosis and during the follow up.

Methods: We retrospectively evaluated PET/CT of 49 patients affected by clinically active LVV according to LVV visual grading (LVG, grading $0-3$ ) and measured the standardized uptake value(SUV) of large vessels. $38(77,6 \%)$ patients were affected by Giant Cells Arteritis and $11(22,4 \%)$ by Takayasu Arteritis. $32(65.3 \%)$ patients repeated the imaging after a mean follow-up of $11.5 \pm 5.4$ months

All baseline (T0) and follow up (T1) clinical data of disease activity were collected. Patients were treated according to EULAR LVV management recommendations(2). TO PET/CT study was performed in patients with a clinically active disease defined by suggestive symptoms/signs and/or high inflammatory markers. The mean disease duration before T1 PET/CT examination was 4 months. TO PET was performed in $25 / 49$ patients(52\%) at the diagnosis of 
LVV, whereas in 24/49(48\%) patients with already diagnosed but active LVV disease.

Results: Baseline PET was positive in 21 patients(42.9\%). According to ASNC recommendations, 19 patients $(38.8 \%)$ presented a $L V G=3,2(4.0 \%)$ a $L V G=2$, $6(12.2 \%) \mathrm{LVG}=1$ and $22(44.9 \%) \mathrm{LVG}=0$. Patients performing PET at disease onset(75\%) had higher LVG score than patients performing PET during the disease course $(25 \%), p=0,002$. At T0, aortic, carotid, axillary and subclavian SUV did not correlate with inflammatory markers.

Follow up PET/CT studies were performed in 32 patients, $13(40.6 \%)$ with a clinically active disease despite therapy, while 19(59.4\%) in clinical remission.

Follow up PET was still positive in 8 patients (25\%) with a LVG=3, 10 (31.2\%) patients presented LVG $=1$ and 14 (43.8\%) $L V G=0$. T1 PET/CT study showed a significant reduction of SUV values in descending aorta, left and right subclavian arteries, and left and right axillary arteries when compared with first PET/ CT study. According to LVG, 12 patients with active PET/CT study at T0 (19 pts) presented a reduction of LVG from score 2 and 3 to grade 1 or $0(64.2 \%)$ at second PET/CT study. Only 3 patients presented an increased LVG score at $\mathrm{T} 1$, while in the other 17 patients T1 PET confirmed the previous score. No significant difference was found between LVG scores according with clinical characteristics, but among 8 patients presenting an active T1 PET, 4(50\%) were in clinical remission.

Conclusion: The use of ASNC recommendations for FDG PET/CT in LVV enables to confirm a metabolically active disease in $40 \%$ of patients and in $75 \%$ of patients at disease onset, suggesting that post-posing the exam could lead to underrate the real extension of disease. Our data, even if limited, suggest that PET/CT could be crucial in management of patients in clinical remission, detecting patients with still metabolically active LVV. Further prospective studies are necessary to evaluate the role of PET/CT in driving therapeutic strategies. References:

[1] Slart R et all - Eur J Nucl Med Mol Imaging, 2018

[2] Hellmich et all - Ann Rheum Dis 2018

Disclosure of Interests: Laura Gigante: None declared, Dario Bruno: None declared, Vanessa Feudo: None declared, Silvia Laura Bosello Speakers bureau: Abbvie, Pfizer, Boehringer, Lucia Leccisotti: None declared, Alessia Musto: None declared, Pier Giacomo Cerasuolo: None declared, Angelo Zoli: None declared, Alessandro Giordano: None declared, Elisa Gremese Speakers bureau: Abbvie, BMS, Celgene, Jannsen, Lilly, MSD, Novartis, Pfizer, Sandoz, UCB DOI: 10.1136/annrheumdis-2020-eular.6176

\section{THU0307 $\quad$ RESPONSE OF BEHCCET'S REFRACTORY ORAL AND/OR GENITAL ULCERS TO APREMILAST IN COMBINATION VS MONOTHERAPY. NATIONAL MULTICENTER STUDY OF 51 CASES OF CLINICAL PRACTICE}

A. Herrero Morant*1, B. Atienza Mateo ${ }^{1}$, J. Loricera ${ }^{1}$, V. Calvo del Rio ${ }^{1}, \mathrm{~J}$. L. Martín-Varillas ${ }^{1}$, J. Graña ${ }^{2}$, G. Espinosa ${ }^{3}$, C. Moriano $^{4}$, T. Pérez Sandoval ${ }^{4}$, M. Martín Martínez ${ }^{4}$, E. Diez ${ }^{4}$, M. D. García-Armario ${ }^{5}$, E. Martínez ${ }^{6}$, I. Castellvi ${ }^{7}$, P. Moya Alvarado ${ }^{7}$, F. Sivera ${ }^{8}$, J. Calvo $^{9}$, I. De la Morena ${ }^{10}$, F. Ortiz Sanjuán ${ }^{11}$, J. A. Román Ivorra ${ }^{11}$, A. Pérez Gómez ${ }^{12}, \mathrm{~S}$. Heredia ${ }^{13}$ A. Olive ${ }^{13}$, Á. Prior ${ }^{13}$, C. Díez ${ }^{14}$, J. J. Alegre-Sancho ${ }^{15}$, D. Ybáñez-García ${ }^{15}$, Á. Martínez-Ferrer ${ }^{15}$, J. Narváez ${ }^{16}$, I. Figueras ${ }^{16}$, A. I. Turrión ${ }^{17}$, S. RomeroYuste $^{18}$, P. Trénor ${ }^{19}$, S. Ojeda ${ }^{20}$, M. Á. González-Gay ${ }^{1}$, R. Blanco ${ }^{1} .{ }^{1}$ H. U. M. Valdecilla, Rheumatology, Santander, Spain; ${ }^{2}$ Centro Médico Quirón, Rheumatology, A Coruña, Spain; ${ }^{3} \mathrm{H}$. Clinic, Autoimmune Diseases, Barcelona, Spain; ${ }^{4}$ Complejo Asistencial Universitario de León, Rheumatology, León, Spain; ${ }^{5} \mathrm{H}$. Luís Alcanyís, Rheumatology and Dermatology, Xàtiva, Spain; ${ }^{6} \mathrm{H}$. Lluís Alcanyís, Rheumatology and Dermatology, Xàtiva, Spain; ${ }^{7} \mathrm{H}$. Santa Creu i Sant Pau, Rheumatology, Barcelona, Spain; ${ }^{8} \mathrm{H}$. General Universitario de Elda, Rheumatology, Elda, Spain; ${ }^{9}$ Hospital Universitario Araba, Rheumatology, Vitoria, Spain; ${ }^{10} \mathrm{H}$. Universitario General de Valencia, Rheumatology, Valencia, Spain; ${ }^{11} \mathrm{H}$. Universitario la Fe, Rheumatology, Valencia, Spain; ${ }^{12} \mathrm{H}$. Príncipe de Asturias, Rheumatology, Alcalá de Henares, Spain; ${ }^{13} \mathrm{H}$. Universitari Germans Trias i Pujol, Rheumatology, Badalona, Spain; ${ }^{14} \mathrm{H}$. Bierzo, Rheumatology, León, Spain; ${ }^{15} \mathrm{H}$. Universitario Doctor Peset, Rheumatology, Valencia, Spain; ${ }^{16} \mathrm{H}$. Bellvitge, Rheumatology and Dermatology, Barcelona, Spain; ${ }^{17} \mathrm{H}$. Clínico Universitario de Salamanca, Rheumatology, Salamance, Spain; ${ }^{18}$ Complejo Hospitalario Universitario de Pontevedra, Rheumatology, Pontevedra, Spain; ${ }^{19} \mathrm{H}$. Clínico Universitario de Valencia, Rheumatology, Valencia, Spain; ${ }^{20} \mathrm{H}$. Doctor Negrín, Rheumatology, Las Palmas de Gran Canaria, Spain

Background: Apremilast (APR) has demonstrated efficacy in the treatment of oral and/or genital aphthous ulcers in Behçet's disease (BD). Combination of APR to other disease-modifying anti-rheumatic drugs (DMARDs) has not been assessed.
Objectives: To compare the efficacy and safety of APR in monotherapy or combined with DMARDs in refractory BD.

Methods: National multicenter open-label study on 51 BD patients with oral and/ or genital ulcers refractory to conventional treatment.

Results: We included 51 patients (35 women/16 men), mean age $44.7 \pm 13.2$ years. Before APR, all patients had received several systemic conventional drugs. The main clinical symptoms for starting APR were oral $(n=19)$ and genital (2) aphthous ulcers or both (30).

Excluding corticosteroids, colchicine or NSAIDs, APR was given at standard dose of $30 \mathrm{mg}$ twice daily in monotherapy $(n=31)$, or combined with conventional DMARDs in 16 cases ( 6 azathioprine, 5 methotrexate, 4 hydroxychloroquine, 4 sulfasalazine, 1 dapsone) or with biologic DMARDs in 4 (2 tocilizumab, 1 adalimumab, 1 infliximab). There were not found statistically significant differences in demographic features, previous therapy, clinical manifestations or reported adverse effects.

After a median follow-up of 6 [3-12] months, most of the patients experienced improvement of the orogenital ulcers in both groups ( $89.8 \%$ in the first 2 weeks) without statistically significant differences. (TABLE)

Conclusion: APR leads to a rapid and maintained improvement in most patients with refractory BD orogenital ulcers. APR seems as effective and safe in monotherapy as combined.

TABLE:

\begin{tabular}{|c|c|c|c|c|c|c|c|c|c|c|}
\hline \multirow[b]{2}{*}{$\begin{array}{l}\text { Outcome of oral and/or } \\
\text { genital ulcers } n,(\%)\end{array}$} & \multicolumn{2}{|c|}{ Week 1-2 } & \multicolumn{2}{|l|}{ Week 4} & \multicolumn{2}{|c|}{ Month 6} & \multicolumn{2}{|c|}{ Month 12} & \multicolumn{2}{|c|}{ Month 24} \\
\hline & $C_{n=19}$ & ${ }_{n=30}^{M}$ & $C_{n=19}$ & $\begin{array}{l}M \\
n=26\end{array}$ & $6 \mathrm{n}=12$ & ${ }_{n=17}^{M}$ & $C_{n=7}$ & $\begin{array}{l}M \quad C \\
n=6\end{array}$ & $\begin{array}{l}C \\
n=1\end{array}$ & $\begin{array}{l}M \\
n=1\end{array}$ \\
\hline Complete resolution & $\begin{array}{c}8 \\
(42.1)\end{array}$ & $\begin{array}{c}11 \\
(36.7)\end{array}$ & $\begin{array}{c}12 \\
(63.2)\end{array}$ & $\begin{array}{c}20 \\
(77)\end{array}$ & $\begin{array}{c}7 \\
(58.4)\end{array}$ & $\begin{array}{c}14 \\
(82.4)\end{array}$ & $\begin{array}{c}3 \\
(42.8)\end{array}$ & $\begin{array}{c}3 \\
(50)(\end{array}$ & $\begin{array}{c}1 \\
(100)\end{array}$ & $\begin{array}{c}1 \\
(100)\end{array}$ \\
\hline Partial resolution & $9(47.4)$ & $\begin{array}{l}167 \\
(53.4)\end{array}$ & $7(36.8)$ & $\begin{array}{c}3 \\
(11.5)\end{array}$ & $5(41.6)$ & $2(11.7)$ & $4(57.2)$ & $\begin{array}{l}3 \\
(50)\end{array}$ & 0 & 0 \\
\hline No response & $\begin{array}{c}2 \\
(10.5)\end{array}$ & $3(9.9)$ & 0 & $\begin{array}{c}3 \\
(11.5)\end{array}$ & ) & $1(5.9)$ & 0 & 0 & 0 & 0 \\
\hline$p$ value & 0. & .9 & 0.1 & & & .1 & 0.8 & & & 0.7 \\
\hline
\end{tabular}

Abbreviations: $\mathrm{C}=$ combined; $\mathrm{M}=$ monotherapy; $\mathrm{n}=$ available data .

Disclosure of Interests: Alba Herrero Morant: None declared, Belen Atienza Mateo: None declared, J. Loricera: None declared, Vanesa Calvo del Rio Grant research support from: MSD and Roche, Speakers bureau: Abbott, Lilly, Celgene Grünenthal, UCB Pharma, José Luis Martín-Varillas Grant/research support from: AbbVie, Pfizer, Janssen and Celgene, Speakers bureau: Pfizer and Lilly Jenaro Graña: None declared, Gerard Espinosa: None declared, Clara Moriano: None declared, Trinidad Pérez Sandoval: None declared, Manuel Martín Martínez: None declared, Elvira Diez: None declared, María Dolores GarcíaArmario: None declared, Esperanza Martínez: None declared, Ivan Castellv Consultant of: Boehringer Ingelheim, Actelion, Kern Pharma, Speakers bureau: Boehringer Ingelheim, Actelion, Bristol-Myers Squibb, Roche, Patricia Moya Alvarado: None declared, Francisca Sivera: None declared, Jaime Calvo Grant/ research support from: Lilly, UCB, Consultant of: Abbvie, Jansen, Celgene, Isabe de la Morena: None declared, Francisco Ortiz Sanjuán: None declared, José Andrés Román Ivorra: None declared, Ana Pérez Gómez: None declared, Sergi Heredia: None declared, Alejandro Olive: None declared, Águeda Prior: None declared, Carolina Díez: None declared, Juanjo J Alegre-Sancho Consultant of: UCB, Roche, Sanofi, Boehringer, Celltrion, Paid instructor for: GSK, Speakers bureau: MSD, GSK, Lilly, Sanofi, Roche, UCB, Actelion, Pfizer, Abbvie, Novartis, D Ybáñez-García Speakers bureau: Lilly, Roche, Sanofi, Ángels Martínez-Ferrer: None declared, J. Narváez: None declared, Ignasi Figueras: None declared, Ana Isabel Turrión: None declared, Susana Romero-Yuste: None declared, Pilar Trénor: None declared, Soledad Ojeda Speakers bureau: AMGEN, LILLY, GEBRO, Miguel Á. González-Gay Grant/research support from: AbbVie, MSD and Roche, Speakers bureau: AbbVie, MSD and Roche, Ricardo Blanco Grant/ research support from: Abbvie, MSD and Roche, Consultant of: Abbvie, Pfizer Roche, Bristol-Myers, Janssen and MSD, Speakers bureau: Abbvie, Pfizer Roche, Bristol-Myers, Janssen, Lilly and MSD

DOI: 10.1136/annrheumdis-2020-eular.6246

\section{THU0308}

\section{COMPARISON OF CHILDHOOD-ONSET VERSUS} ADULT-ONSET TAKAYASU ARTERITIS: A STUDY OF 141 PATIENTS FROM TURKEY

M. Karabacak ${ }^{1}$, S. Kaymaz Tahra ${ }^{1}$, S. Sahin², M. Yildiz², A. Adrovic ${ }^{2}$, K. Barut ${ }^{2}$, H. Direskeneli ${ }^{1}$, O. Kasapcopur ${ }^{2}$, F. Alibaz-Oner ${ }^{1} .{ }^{1}$ Marmara University Faculty of Medicine, Rheumatology, Istanbul, Turkey; ${ }^{2}$ Cerrahpasa Medical School, Istanbul University-Cerrahpasa, Pediatric Rheumatology, Istanbul, Turkey 